Bayu Dwi Nurwicaksono: Folklor Lapindo sebagai Wawasan

\title{
FOLKLOR LAPINDO SEBAGAI WAWASAN GEO-CULTURE DAN GEO-MYTHOLOGY BERBASIS KEARIFAN LOKAL DALAM PEMBELAJARAN BAHASA INDONESIA BAGI PENUTUR ASING (BIPA)
}

\author{
Bayu Dwi Nurwicaksono \\ FPBS, Universitas Negeri Surabaya \\ Korespondensi: Jl. Ketintang, Surabaya 60231, Jawa Timur \\ pos-el: byupbsi_unesa@yahoo.co.id
}

\begin{abstract}
Abstrak
Kearifan lokal tentang insiden lumpur Lapindo adalah cerita rakyat tentang kejadian di masa lalu yang dapat digunakan sebagai pelajaran pada masa kini dan masa depan, tentang dongeng Candi Tawangalun dan dongeng Emas Ketimun. Terlepas apakah itu sebuah dongeng yang pernah terjadi secara empiris atau hanya realitas-fiksi, kehadirannya dapat digunakan sebagai pijakan untuk memahami peristiwa (bencana) dari perspektif budaya. Wawasan Geo-Budaya dan Geo-Mitologi dalam cerita rakyat Lapindo bisa menjadi alternatif bahan pembelajaran kontekstual berbasis kearifan lokal dalam pembelajaran bahasa Indonesia untuk penutur asing karena kontekstualitas dan substansi nilai-nilai yang terkandung di dalamnya sangat menarik. Praktek pembelajaran bahasa Indonesia untuk penutur asing di Australia diketahui bahwa cerita tradisi lisan tapi cerita hanya sebagai pelengkap tradisi lisan sama pentingnya dengan pengetahuan tentang tata bahasa, bahkan dengan pengenalan tradisi lisan cerita, pembelajar BIPA akan mengetahui tentang budaya Indonesia.
\end{abstract}

Kata-kata kunci: cerita rakyat, Geo-Culture, Geo-Mythology, kearifan lokal, BIPA

\begin{abstract}
Local wisdom about Lapindo mudflow incident is the folklore about the events in the past that can be used as a lesson on the present and future, that fairy tales Tawangalun Temple and fairy tale Golden Cucumber. Regardless whether it's a fairy tale ever happened empirically or just reality-fiction, its presence can be used as a foothold for understanding the events (disasters) from the perspective of the present culture. Insights Geo-Culture and Geo-Mythology in Lapindo folklore can be an alternative contextual teaching materials based on local wisdom in learning Indonesian for foreign speakers because contextuality and substance of the values contained in it very interesting. Practice learning Indonesian for foreign speakers in Australia is known that oral tradition story but the story only as a complement to the oral tradition is just as important as knowledge of grammar, even with the introduction of the oral tradition of story, BIPA learners will know the culture of Indonesia.
\end{abstract}

Keywords: folklore, Geo-Culture, Geo-Mythology, local wisdom, BIPA 



\section{PENDAHULUAN}

Kearifan lokal sering menjadi refleksi atas suatu bencana alam yang terjadi akhir-akhir ini. Ulasan mengenai bencana kini sering menempatkan kearifan lokal sebagai sesuatu yang penting dipahami. Hal itu didasarkan pada kenyataan bahwa teknologi belum mampu menjawab semua persoalan. Tajuk Rencana pada Harian Kompas (2010) pernah menulis "Fenomena Mbah Maridjan" yang intinya membawa pesan agar tidak hanya memutlakkan analisis-rasional, tetapi juga melengkapkan kearifan lokal dalam analisis-rasional dalam mitigasi, seismologi, vulkanologi. Kearifan lokal yang tampaknya irasional pada hakikatnya merupakan representasi kebersatuan psikis dan kultural manusia dengan alam.

Lampe (2006) menyebutkan bahwa kearifan lokal merupakan gagasan/pandangan, pengetahuan, kepercayaan, nilai, norma, moral dan etika, kelembagaan (melibatkan norma, praktik atau tindakan berpola,organisasi), dan teknologi yang menyumbang kepada tercipta dan tetap terpeliharanya kondisi tatanan kehidupan masyarakat di berbagai bidang, kemajuan, dan terjaganya kondisi ekosistem lingkungan dan sumber daya sehingga pemanfaatannya oleh kelompok atau komunitas manusia (sebagai salah satu komponen ekosistem) berlangsung secara berkesinambungan.

Kearifan lokal mengandung tiga unsur penting. Pertama, nilai religius dan etika sosial yang mendasari praktik-praktik pengelolaan sumber daya hayati. Kedua, norma/aturan adat, yang mengatur hubungan antarkomunitas dan lingkungan alam. Ketiga, pengetahuan lokal dan keterampilan yang diperoleh dari pengalaman empirik berpuluh-puluh bahkan beratus-ratus tahun mengelola sumber daya hayati dan lingkungan.
Sementara itu, pemahaman mengenai folklor yang dikemukakan Danandjaja (2008) adalah “... sebagian kebudayaan suatu kolektif, yang tersebar dan diwariskan turun temurun, di antara kolektif macam apa saja, secara tradisional dalam versi yang berbeda, baik dalam bentuk lisan maupun yang disertai dengan gerak isyarat atau alat pembantu pengingat. Folklor memiliki beberapa ciri pengenal seperti (a) penyebaran dan pewarisannya bersifat lisan; (b) bersifat tradisional; (c) ada (eksis) dalam berbagai versi dan varian yang berbeda; (d) bersifat anonim; (e) biasanya mempunyai bentuk berumus; (f) mempunyai kegunaan (fungsi) dalam kehidupan bersama kolektifnya; (g) bersifat pralogis; (h) milik bersama (kolektif); dan (i) pada umumnya bersifat polos dan lugu.

Bagian dari kebudayaan yang disebut folklor itu dapat berupa ujaran rakyat, ungkapan tradisional (peribahasa, pepatah), teka-teki, cerita prosa seperti mitos, legenda dan dongeng (termasuk anekdot dan lelucon), nyanyian rakyat, teater rakyat, permainan rakyat, kepercayaan/keyakinan rakyat, arsitektur rakyat, seni rupa dan seni lukis rakyat, musik rakyat, gerak isyarat (gesture), dan sebagainya. Dalam Kamus Besar Bahasa Indonesia (2005) folklor didefinisikan sebagai adat-istiadat tradisional dan cerita rakyat yang diwariskan turun-temurun, tetapi tidak dibukukan.

Dalam falsafah Jawa terdapat istilah sadhumuk bathuk senyari bumi ditohi pati (sejengkal tanah akan dibela sampai mati). Itu artinya keterikatan warga dengan tanah tumpah darahnya tidak dapat tergantikan dengan uang berapapun. Dalam kasus lumpur Lapindo, tanah penduduk lenyap bukan karena dirampas oleh seorang penguasa. Lenyapnya tanah pertanian dan tempat tinggal penduduk disebabkan kelalaian 
suatu perusahaan yang menyebabkan musibah. Pandangan orang Jawa mengenai sadhumuk bahtuk itu masih terlihat dalam kasus lumpur Lapindo.

\section{METODE}

Metode yang digunakan dalam tulisan ini adalah metode deskriptif. Metode ini digunakan untuk mendeskripsikan folklor sebagai wawasan geo-culture dan geo-mythology berbasis kearifan budaya lokal.

\section{PEMBAHASAN}

Bentuk kearifan lokal dalam semburan lumpur Lapindo bukan berupa ajaran atau tradisi lisan yang memperingatkan datangnya bencana. Kearifan lokal di Porong ini berupa dongeng mengenai peristiwa pada masa lampau yang dapat digunakan sebagai pelajaran pada masa mendatang. Terlepas apakah dongeng itu pernah terjadi secara empiris atau hanya realitas-fiksi, keberadaannya dapat digunakan sebagai pijakan untuk memahami kejadian (bencana) masa kini dari perpektif budaya.

\section{Wawasan Geo-Culture Berbasis Kearifan Lokal}

Catatan sejarah-sastra bahwa Kerajaan Jenggala tenggelam oleh bencana banjir menarik dikaji. Kitab Pararaton terjemahan Brandes (1896) dalam Nurcahyo (2010) menyebutkan bahwa pada 1296 Caka atau 1374 Masehi telah terjadi bencana bernama "Pagunung Anyar" yang memundurkan Majapahit. Penelitian Nash (1930) dalam Nurcahyo (2010) menyatakan bahwa tanah Delta Brantas tidak stabil karena di bawahnya masih bergerak tujuh jajaran antiklin yang menyambungkan ujung Pegunungan Kendeng dengan Selat Madura.

Semburan semacam lumpur Lapindo sebenarnya juga terjadi di
Kecamatan Sedati, tepatnya di antara Desa Buncitan Tani dengan Desa Gunung Rejo. Di tempat itu terdapat bangunan semacam menara pengawas semburan atau tempat ritual pemujaan yang kini dikenal dengan Candi Tawangalun. Pada zaman dahulu, tampaknya tempat tersebut dijadikan sebagai tempat untuk berdoa kepada Yang Mahakuasa guna meminta keselamatan dari bencana semburan lumpur. Begitu pun dengan Candi Pari di Porong.

Sekaitan dengan keberadaan candi itu terdapat cerita tentang anak raksasa yang menikah dengan raja. Berikut cerita yang berkembang di masyarakat sesuai dengan yang disampaikan Ahmad Syaiful Munir, juru kunci candi.

Pada masa Raja Brawijaya II (1292) daerah Buncitan termasuk daerah kerajaan Majapahit yang paling ujung (Buncitan dalam bahasa Jawa, berarti: terakhir) karena berhadapan langsung dengan laut. Di desa Buncitan ada orang tua yang bernama Resi Tawangalun, dia memiliki seorang putri bernama Putri Alun. Daerah Buncitan dalam legenda termasuk daerah para "Buto", tidak jelas bentuknya yang menyerupai Buto (raksasa) atau hanya perwatakannya yang seperti Buto beringasan.

Ketika sang Prabu menyinggahi daerah Buncitan untuk melihat daerah kekuasaannya, ternyata Putri Alun menaruh hati pada sang raja. Dengan kondisi fisik yang menyerupai Buto tentu tidak mungkin Prabu Brawijaya akan tertarik padanya. Melihat gejala tersebut akhirnya dengan kesaktiannya, Resi Tawangalun mengubah perawakan putrinya seakan-akan menjadi cantik jelita. Dari situlah awal ketertarikan Prabu Brawijaya pada Putri Alun sehingga dijadikan selir dan diboyong ke Kota Raja.

Sebagai bentuk cintanya kepada Putri Alun, sang Prabu 
memerintahkan kepada warga Buncitan untuk membangun sebuah candi di daerah tersebut. Tentu dengan senang hati warga Buncitan bergotong royong membangun candi sebagai bentuk cinta dan pengabdiannya kepada raja.

Waktu terus berjalan akhirnya sang Putri hamil, begitu senang hati sang Prabu mendengar kabar tersebut, tetapi seiring pertumbuhan janin, Putri Alun terlihat aneh, yakni sang Putri memiliki kebiasaan suka makan daging mentah dan lain-lain yang tidak seperti manusia biasa hamil. Mengetahui hal tersebut akhirnya sang prabu mengusir Putri Alun dari Kota Raja, karena raja tidak ingin memiliki selir yang berperilaku seperti Buto, apalagi dia sedang mengandung.

Dengan kondisi hamil tua akhirnya Putri Alun kembali pulang ke Buncitan ke tempat ayahnya berada. Sesampainya di sana, dia menceritakan apa yang telah dialami selama menjadi selir Prabu Brawijaya. Resi Tawangalunpun menanggapi dengan bijak bahwa hal tersebut merupakan suratan takdir yang harus dihadapinya. Selama menunggu kelahiran sang bayi dia sering menenangkan diri di candi yang dibuatkan Raja untuknya.

Akhirnya Putri Alun pun melahirkan seorang putra dan diberi nama Joko Dilah alias Arya Damar. Karena masih teringat akan perlakuan sang Prabu, Putri Alun meminta kepada ayahnya untuk tidak menceritakan siapa ayah kandung Arya Damar. Sejak kecil Arya Damar diasuh oleh ibu dan kakeknya. Dia tidak pernah mendapatkan kasih sayang dari seorang ayah. Namun, berkat gemblengan dari kakeknya, Arya Damar tumbuh menjadi sosok yang sakti.

Waktu terus berjalan, Arya Damar pun semakin dewasa dan terus menanyakan kepada ibunya, siapa ayahnya? Karena selalu tidak pernah diberi jawaban atas pertanyaannya tersebut Arya Damar dengan kesaktiannya membuat sebuah lampu dari besi (waktu itu lampu dari bahan alami). Guna menarik perhatian orang agar datang ke Buncitan, tetapi hal tersebut tidak membuahkan hasil, dia masih belum menemukan siapa ayah kandungnya.

Melihat upaya yang dilakukan oleh cucunya, Resi Tawangalun menjadi kasihan dan memberi tahu bahwa sesungguhnya Arya Damar adalah putra Prabu Brawijaya. Begitu senang Arya Damar mendengar penjelasan dari sang kakek siapa ayah kandungnya tersebut, dia pun meminta ijin untuk menemui ayahandanya di Kota Raja.

Sesampainya di Kota Raja, Arya Damar menghadap sang Prabu dan mengaku bahwa dia adalah putranya dari selir yang bernama Putri Alun dari daerah Buncitan. Tentunya sang Prabu masih ingat tentang selirnya yang dia usir dari Kota Raja karena berperilaku aneh saat mengandung. Guna membuktikan kebenaran dari pengakuan Arya Damar sang Prabu memerintahkan pada Arya Damar untuk mengambil segenggam tanah dari daerah Buncitan, jika sama dengan tanah di Trowulan maka dia akan diakui sebagai anaknya.

Akhirnya Arya Damar kembali pulang ke Buncitan untuk mengambil tanah kelahirannya dan ditunjukkannya pada sang Prabu. Ternyata memang sama tanah yang dibawa oleh Arya Damar dengan tanah di Trowulan. Di luar dugaan ternyata sang Prabu tidak mengakui Arya Damar sebagai anaknya, karena dia tahu benar bahwa tanah di Buncitan itu asin sebab dekat laut, mengapa tanah yang dibawa Arya Damar rasanya tawar seperti tanah di Trowulan. Melihat penolakan dari ayahnya Arya Damar kembali ke 
Buncitan dan bersemedi di Candi Tawang Alun, kemudian menghilang entah ke mana.

Fenomena kisah Arya Damar itu masih bisa dibuktikan sekarang, yakni di Desa Duran, tanah yang berada sebelah timur sungai terasa asin sedangkan di sebelah barat sungai terasa tawar dan subur. Konon Arya Damar mengambil tanah yang dari sebelah barat sungai. Nah, apakah keberadaan candi dan semburan lumpur di lokasi yang sama itu hanya suatu kebetulan belaka? Keduanya sama-sama terjadi sejak ratusan tahun yang lalu.

Anggota Ikatan Ahli Geologi Indonesia (IAGI) Jatim, Sofyan (2010) menyatakan semburan yang terjadi di Porong, Sedati, Gunung Anyar Surabaya hingga Kecamatan Geger Bangkalan termasuk satu garis patahan. Dalam sejarah, mиd volcano pernah terjadi, berdasarkan peta geologi buatan Belanda 1938 memperlihatkan bahwa di peta Sidoarjo terdapat dua "mudvolcano" (gunung lumpur) di daerah Gedangan. Satu di Poeloengan dan satu lagi di Desa Betro, Buncitan, Kalang Anyar. Blok Brantas (lokasi eksplorasi dan ekploitasi Lapindo) berada pada jalur "Active Mudvolcano" yang membentang dari Purwodadi-Cepu-Bojonegoro-Porong. Fenomena gunung lumpur juga didapati di Sangiran, Kuwu Purwodadi (masih aktif menyembur sampai sekarang), Tuban, Koneng, Bangkalan, Gunung Anyar di Rungkut Surabaya (masih aktif), Gedangan Sidoarjo, Banjarpanji fase erupsi besar, sebelah utara Probolinggo, sebelah utara Bali sampai sebelah utara Lombok (NTB). Tiga lokasi terakhir ini semuanya di bawah permukaan laut. Itulah yang disebut Geo-culture, yakni mengaitkan relevansi antara culture suatu wilayah dengan kejadian geologi.

\section{Wawasan Geo-Mythology Berbasis}

\section{Kearifan Lokal}

Terkait dengan danau lumpur yang disebut Lumpur Lapindo, ada cerita rakyat atau dongeng mengenai Timun Emas. Berikut ceritanya.

Dalam dongeng itu dikisahkan ada seorang wanita, yakni Mbok Sirni. Ia seorang janda yang menginginkan seorang anak agar dapat membantunya bekerja. Suatu hari ia didatangi oleh raksasa yang ingin memberi seorang anak dengan syarat apabila anak itu berusia enam tahun harus diserahkan kepada raksasa itu untuk disantap. Mbok Sirni pun setuju.

Raksasa kemudian memberinya biji mentimun agar ditanam dan dirawat. Setelah dua minggu, di antara buah ketimun yang ditanamnya ada satu yang paling besar dan berkilau seperti emas. Kemudian Mbok Sirni membelah buah itu dengan hati-hati. Ternyata berisi seorang bayi cantik yang diberi nama Timun Emas.

Semakin hari Timun Emas tumbuh menjadi gadis jelita. Suatu hari datanglah raksasa untuk menagih janji. Mbok Sirni amat takut kehilangan Timun Emas, dia mengulur janji agar raksasa datang dua tahun lagi, karena semakin dewasa, semakin enak untuk disantap. Raksasa pun setuju.

Mbok Sirnipun semakin sayang pada Timun Emas, setiap kali ia teringat kepada janjinya, ia menjadi cemas dan sedih. Suatu malam Mbok Sirni bermimpi, agar anaknya selamat ia harus menemui petapa di Gunung Gundul. Paginya ia langsung pergi. Di Gunung Gundul ia bertemu seorang petapa yang memberinya empat buah bungkusan kecil, yakni biji mentimun, jarum, garam, dan terasi sebagai penangkal. Sesampainya di rumah diberikannya empat bungkusan tadi kepada Timun Emas dan disuruhnya berdoa. 
Paginya raksasa datang lagi untuk menagih janji. Timun Emas pun disuruh ke luar lewat pintu belakang oleh Mbok sirni. Raksasa pun mengejarnya. Timun Mas teringat bungkusannya, maka ditebarnya biji mentimun. Sungguh ajaib, hutan menjadi ladang mentimun yang lebat buahnya. Raksasa memakannya dengan lahap, tapi buah timun itu malah menambah tenaga raksasa. Lalu Timun Emas menaburkan jarum, dalam sekejap tumbuhlah pohon-pohon bambu yang sangat tinggi dan tajam. Dengan kaki yang berdarah-darah raksasa terus mengejar. Timun Emas lantas membuka bingkisan garam dan ditaburkannya. Seketika hutan menjadi lautan luas.

Dengan kesakitannya raksasa dapat melewati. Yang terakhir, Timun Emas akhirnya menaburkan terasi, seketika terbentuklah lautan lumpur yang mendidih, akhirnya raksasa mati tenggelam dalam kubangan lumpur sehingga Timun Emas dan Mbok Sirni hidup bahagia dan damai.

Kini yang perlu direnungkan adalah mengapa dalam dongeng itu ada imajinasi lautan lumpur? Pada umumnya dongeng tercipta berdasarkan fakta yang ada sebelumnya. Inilah yang disebut Geo-Mythology. Dongeng Timun Emas, jika dicermati merupakan varian Cerita Panji. Pada dasarnya Cerita Panji adalah sekumpulan cerita pada masa Hindu-Budha di Jawa yang berkisah seputar kisah asmara Panji Asmorobangun dari Kerajaan Jenggala dan Puteri Candrakirana (Dewi Sekartaji) dari Kerajaan Kadiri. Dongeng Timun Emas merupakan varian Cerita Panji sedangkan tokoh Panji Asmorobangun itu adalah seorang pangeran dari Kerajaan Jenggala yang berpusat di Sidoarjo sekarang, jadi benang merahnya adalah pada masa kerajaan Jenggala pernah terjadi bencana lautan lumpur di wilayah sekitar itu, sehingga menginspirasi lahirnya dongeng Timun Emas tersebut

Sebagai telaah komparasi, buku "Benua Atlantis" karya Prof. Arysio Santos yang menghebohkan adalah salah satu contohnya. Santos (2010) banyak mempergunakan sumber-sumber tradisi lisan untuk memperkuat teorinya bahwa benua Atlantis yang hilang itu sesungguhnya adalah Indonesia. Pada buku "Eden in the East" karya Profesor asal Oxford, Inggris, Stephen Oppenheimer yang baru terbit juga menimbulkan kontroversi, namun hal itu justru semakin memperkuat tesis Prof. Santos tentang Atlantis yang hilang itu. Oppenheimer yang juga anggota tim Prof. Santos adalah pakar genetika yang sekaligus mendalami antropologi dan folklor yang mengkaji dongeng-dongeng dunia. Oppenheimer (2010) mencatat ada sekitar 500 kisah soal banjir di seluruh dunia. Dari India sampai Amerika, dari Australia sampai Eropa. Tingkat keberagaman cerita banjir di kawasan ini pun membuat Oppenheimer berteori, kalau bangsa yang terpaksa berimigrasi akibat banjir besar ialah Indonesia dan sekitarnya.

Dengan mengemukakan ilustrasi soal Atlantis dan Sundaland itu dapat disimpulkan bahwa realitas-fiksi dongeng Timun Emas itu sesungguhnya tidak dapat diremehkan, khususnya tentang adanya (semacam) banjir lumpur sekian abad yang lalu di kawasan kerajaan Jenggala atau Sidoarjo sekarang.

\section{Wawasan Geo-Culture dan Geo-Mythology dalam Pembelajaran BIPA}

Menurut Pollard (2003), di antara buku-buku terbitan Australia untuk tingkat madya yang menggunakan tradisi lisan adalah buku karangan McGarry dan Sumaryono (1994) yang membawakan 
cerita Kancil dan cerita Ken Arok. Soewito Santosa dan Sumaryono (1979) membawakan cerita Sangkuriang dan Lorojonggrang. White (1989) dan Hibbs (1998) masing-masing menggunakan cerita Nyai Roro Kidul dan Tangkuban Perahu. Herdie (2001) menggunakan empat cerita tradisi lisan, yakni Dewi Sri, Dongeng Minangkabau, Si Kancil yang Cerdik, dan cerita Seekor Kura-kura dan Dua Ekor Angsa.

Menurutnya, cerita tradisi lisan memiliki keunggulan dan kelemahan dalam konteks pembelajaran Bahasa Indonesia bagi Penutur Asing (BIPA). Keunggulannya adalah sampai kapan pun tradisi lisan bisa dipakai karena memiliki nilai-nilai universalitas, bentuk pembelajaran dapat dibuat secara menyenangkan dengan bermain peran, nilai-nilai moral dan budaya yang terkandung dalam cerita tradisi lisan dapat diinternalisasi secara mendalam dan mengesankan oleh siswa. Sementara itu kelemahannya adalah kadangkala dalam cerita tradisi lisan terdapat cerita yang mengandung kekerasan.

Berdasarkan pengalamannya mengajarkan bahasa Indonesia untuk penutur asing di Australia itu ia menyatakan bahwa cerita tradisi lisan dalam pengajaran bahasa Indonesia hanya sebagai pelengkap. Menurutnya semua komponen pengajaran bahasa Indonesia termasuk tata bahasa dan cerita tradisi lisan sama pentingnya. Hal itu dikuatkan Bascom (1965) bahwa tradisi lisan mencerminkan suatu aspek kebudayaan, baik yang langsung maupun tidak langsung dengan tema-tema kehidupan mendasar, seperti kelahiran, kehidupan keluarga, penyakit, kematian, penguburan, dan malapetaka atau bencana alam.

Karena itu, wawasan geo-culture dan geo-mythology yang terdapat dalam folklor Lapindo dapat menjadi bahan ajar dalam pembelajaran bahasa Indonesia bagi penutur asing kekinian sebab kontekstualitas dan substansi nilai-nilai yang terkandung di dalamnya sangat menarik.

\section{SIMPULAN}

Berdasarkan data cerita tradisi lisan, pengalaman penggunaan cerita tradisi lisan sebagai media pembelajaran BIPA, dan teori kemanfaatan yang telah dipaparkan di atas dapat disimpulkan bahwa wawasan Geo-Culture dan Geo-Mythology dalam folklor Lapindo dapat menjadi alternatif bahan ajar yang kontekstual berbasis kearifan lokal yang menarik dalam pembelajaran bahasa Indonesia bagi penutur asing sebab bencana lumpur Lapindo sampai saat ini masih menjadi bahan pembicaraan oleh banyak kalangan masyarakat baik di dalam maupun luar negeri.

Karena itu, disarankan kepada pemerhati pendidikan agar terus menggali kearifan-kearifan lokal di Indonesia yang dapat dijadikan sumber belajar dan khusus kepada pengajar bahasa Indonesia bagi penutur asing disarankan agar memanfaatkan cerita tradisi lisan Indonesia sebagai upaya mengenalkan budaya bangsa melalui bahasa Indonesia.

\section{UCAPAN TERIMA KASIH}

Penulis mengucapkan terima kasih kepada semua pihak yang telah membantu sehingga tulisan ini dapat dimuat, terutama kepada redaksi jurnal Bahasa \& Sastra.

\section{PUSTAKA RUJUKAN}

Bascom, W.R. 1965.The Form of Folklore: Prose Narratives. Journal of American Folklore. The Hague: Mouton.

Danandjaja, James. 2008. Folklor 
Indonesia: Ilmu Gosip, Dongeng dan Lain-lain. Jakarta: PT. Pustaka Utama Grafiti.

Lampe, Munsi. 2006. Kearifan Tradisional Lingkungan: Belajar dari Kasus-kasus Komunitas Petani dan Nelayan Tradisional. Makalah Lokakarya Menggali Kearifan Lingkungan Nelayan di Sulawesi Selatan. PPLH Regional Semapapua, Makassar.

Nurcahyo, Henri. 2010. Folklor Lumpur Lapindo. Makalah Konferensi Internasional Tradisi Lisan di Bangka Belitung.

Oppenheimer, Stephen. 2010. Eden in the East. Jakarta: Ufuk Press.
Pollard, Nani. 2003. Pengajaran Bahasa Indonesia untuk Pembelajar Asing melalui Cerita Tradisi Lisan. Makalah Konferensi Internasional Pengajaran Bahasa Indonesia bagi Penutur Asing IV di Bali.

Pusat Bahasa Kemdiknas. 2005. Кamus Besar Bahasa Indonesia. Jakarta: Balai Pustaka.

Santos, Arysii. 2010. Atlantis: The Lost Continent Finally Found. Jakarta: Ufuk Press.

Sofyan, Hadi. 2010. Bencana Lumpur Lapindo dalam Perspektif Budaya. Milis Ikatan Ahli Geologi Indonesia (IAGI).

Tajuk, Rencana. Sabtu, 30 Oktober 2010. Fenomena Mbah Maridjan. Jakarta: Harian Kompas. 